Conclusion In acute exacerbation of COPD there is no difference between 7-day and 14-day courses of treatment with oral prednisolone. The peak of $\mathrm{FEV}_{1}$ and FVC in 7-day group on day-10 where corticosteroid was already stopped on day-7, (peak in 14-day group was on day-7) might be due to some other factor/factors responsible which would be cleared by further study.

Clinical implications There was no difference between 7-day and 14day courses of prednisolone treatment, so, 7-day might be the shortest effective course of steroid treatment in acute exacerbation of COPD to avoid the burden of cost and side effects.

\section{P259 EFFECTS OF METFORMIN ON CLINICAL OUTCOME IN PATIENTS HOSPITALISED FOR COPD EXACERBATIONS: A RETROSPECTIVE COHORT STUDY}

doi:10.1136/thoraxjnl-2011-201054c.259

A W Hitchings, L Hayes, G Picton, L Turner, R Cull, S Aslam, J R H Archer, S A Srivastava, E H Baker. St George's, University of London, London, UK

Background Approximately 10\% of patients with chronic obstructive pulmonary disease (COPD) have co-existing diabetes mellitus, conferring an adverse prognosis. Metformin is a valuable first-line treatment for diabetes. However, its rare association with lactic acidosis limits its use among patients at risk of hypoxia. This may deter some practitioners from prescribing it to patients with significant co-existing COPD. It is unknown whether the benefits of metformin outweigh its risks in this context. We therefore sought to determine the effects of metformin on survival and length of stay in a high-risk cohort of diabetic patients hospitalised for COPD exacerbations.

Methods The medical records of diabetic patients hospitalised for COPD were reviewed retrospectively. Length of hospital stay and all-cause mortality were compared according to the presence or absence of metformin therapy.

Results 130 patients were included, of whom 51 (39\%) were prescribed metformin. Patients on metformin had a shorter hospital stay (median 7 vs 9 days respectively; $\mathrm{p}=0.004$ ). Survival at 90 days was significantly better in the metformin group than in the nonmetformin group (94\% vs $78 \%$ respectively; $\mathrm{p}=0.015$; Abstract $\mathrm{P} 259$ figure 1 inset). This persisted over the longer term, with overall median $(95 \% \mathrm{CI})$ survival of 5.2 years (4.3 to 6.1$)$ in the metformin group and 2.2 years (1.0 to 3.3 ) in the non-metformin group (HR

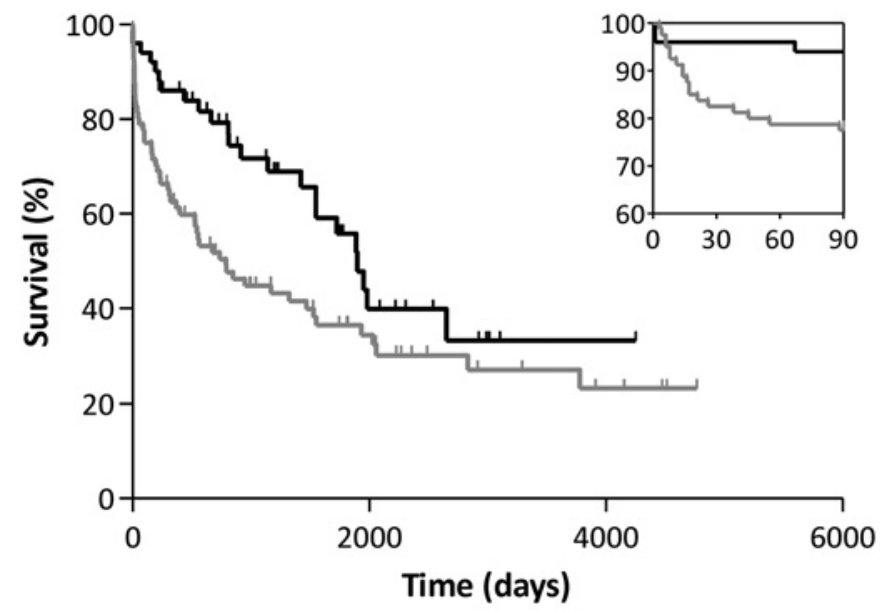

- Metformingroup - Non-metformin group

Abstract P259 Figure 1 Kaplan-Meier curves for all-cause mortality, divided according to metformin use ( $p=0.024$, log-rank test). Inset: survival curves at 90 days ( $p=0.015$, log-rank test).
0.57; 95\% CI 0.35 to 0.94; Abstract P259 figure 1). This difference remained significant in a multivariate model, adjusting for potential confounding effects of age, weight, acute illness severity (APACHEII score) and comorbidity burden. Among patients prescribed metformin, vs those not, the median (IOR) plasma lactate concentration was $1.45 \mathrm{mmol} / \mathrm{l}(1.10-2.05)$ vs $1.10 \mathrm{mmol} / \mathrm{l}(0.80-1.50)$, respectively $(\mathrm{p}=0.012)$.

Conclusion Diabetic patients hospitalised for COPD exacerbations who were prescribed metformin were discharged earlier and survived longer than those not prescribed metformin. Lactate concentration was higher among patients on metformin, although the difference was small. Our results suggest that the drug's benefits may outweigh its rare association with lactic acidosis. Whether this reflects beneficial effects on diabetes- or COPD-related endpoints; other associated conditions; or the effect of unmeasured confounders, is unknown. We are now investigating this within the context of a randomised controlled trial (ISRCTN66148745).

\section{P260 ORAL NUTRITIONAL SUPPLEMENTS IN CHRONIC OBSTRUCTIVE PULMONARY DISEASE (COPD): A SYSTEMATIC REVIEW AND META-ANALYSIS}

doi:10.1136/thoraxjnl-2011-201054c.260

P F Collins, R J Stratton, M Elia. Institute of Human Nutrition, School of Medicine, University of Southampton, Southampton, England

Oral nutritional supplements (ONS) are often used to treat malnutrition in COPD, but the latest Cochrane review in COPD concluded that nutrition support, mainly involving ONS, did not improve anthropometry and other functional outcomes. ${ }^{1}$ The latest NICE guidelines for the management of COPD recommend the use of ONS but state it is based on grade $\mathrm{D}$ evidence ${ }^{2}$ despite previous reviews suggesting otherwise. ${ }^{3}$ This review aimed to clarify the evidence base for ONS use in COPD. A systematic review identified 11 randomised controlled trials using ONS vs control (189 vs 185). Meta-analysis was performed of nutritional intake, weight, mid-arm muscle circumference (MAMC) and handgrip strength (HGS) (Comprehensive Meta-analysis v2). Quality of life, exercise capacity and respiratory outcomes were also examined. In contrast to previous Cochrane reviews, examining only data at the end of intervention, ${ }^{1}$ this review examined the changes induced by ONS. Significantly improved energy intake was reported in six out of seven studies of which four were meta-analysable (+262 SE $104 \mathrm{kcal} / \mathrm{d}, \mathrm{p}=0.012$, random effect model, four RCT). Meta-analysis found ONS significantly improved body weight (+1.85 kg SE $0.25 \mathrm{~kg}, \mathrm{p}<0.001$ (malnourished) and $+1.31 \mathrm{~kg}$ SE $0.34 \mathrm{~kg}, \mathrm{p}<0.001$ (nourished), 11 studies) and had a tendency to improve MAMC $\left(+0.21 \mathrm{~kg}\right.$ SE $0.19 \mathrm{~kg}, \mathrm{p}=0.277$, fixed effect model; $\mathrm{I}^{2}=0 ; 2$ studies $)$. Improved HGS was found in three of four studies, two significant in their own right with meta-analysis favouring ONS $(+2.14 \mathrm{~kg} \mathrm{SE}$ $1.1 \mathrm{~kg}, \mathrm{p}=0.054$, random effect model ( $+8.3 \%$ improvement)). No improvements were reported in $\mathrm{FEV}_{1}$ (eight studies) however, respiratory muscle strength appeared more responsive to ONS with PI max improved in three out of five studies (NS), PE max significantly improved in two out of four studies and sternomastoid strength significantly improved in one study. Exercise tolerance (six out of seven studies), dyspnoea and general well-being (three out of five studies) and quality of life (two out of two studies) were significantly improved with ONS although meta-analysis of these outcomes was not possible. ONS result in significant improvements in nutritional intake and body weight and a tendency for improvements in several functional outcomes. This would support an increased level of evidence for ONS in the NICE COPD guidelines. 


\section{REFERENCES}

1. Ferreira I, et al. Cochrane Database Syst Rev 2005;(2).

2. National Clinical Guideline Centre. Clinical Guideline 101 (CG101). 2010.

3. Stratton RJ, et al. Disease-Related Malnutrition: An Evidence-Based Approach to Treatment. Oxford: CABI, 2003.

\section{P261 DOES THE PROVISION OF A RESCUE PACK KEEP PATIENTS WITH CHRONIC OBSTRUCTIVE PULMONARY DISEASE (COPD) AT HOME?}

doi:10.1136/thoraxjnl-2011-201054c.261

L E E Schomberg, J L Garner, J W Porter, K Bahadur, L Ross, C A Kosky, A C Davidson. Guy's and St Thomas' NHS Foundation Trust, London, UK

Introduction COPD accounts for one in eight hospital admissions, 1 million bed days and costs $£ 870-930 \mathrm{~m}$ a year. ${ }^{1}$ Early treatment of exacerbations with steroids reduces severity and may reduce the need for hospital admission. ${ }^{2}$ We evaluated the acceptance and use of a rescue pack provided on discharge from hospital.

Methods 38 patients, discharged between 1 February and 30 June 2011, were supplied a 7 day rescue pack comprising Prednisolone $25 \mathrm{mg}$ and Doxycycline $100 \mathrm{mg}$ (total cost of £7) with education and a self-management plan.

A telephone questionnaire was conducted in July:

1. Do you remember being given a rescue pack on discharge from hospital?

2. Have you had a flare-up of your COPD since discharge?

3. Did you use your rescue pack?

4. Did you take both antibiotic and steroid?

5. Did you complete the course?

6. Do you think it helped keep you at home?

7. Have you got a replacement rescue pack?

Results 25 out of 38 (66\%) patients were contactable. 11 (44\%) were male and 14 (56\%) female. The median age was 77 (range 53-89) years. The median time from discharge to telephone contact was 110 (range 21-168) days. 24 (96\%) patients acknowledged receipt of the rescue pack. 14 out of $15(93 \%)$ patients who had experienced an exacerbation of COPD had used the rescue pack. Of these 14 patients, 13 (93\%) were confident of the benefit and $10(71 \%)$ had obtained a replacement pack. Six of the $38(16 \%)$ patients supplied with a rescue pack were re-admitted with an exacerbation.

Conclusions The results of this service evaluation suggest a costeffective initiative that may reduce hospital re-admission by promoting earlier treatment. Rescue packs should be supported by education and a self-management plan.

\section{REFERENCES}

1. National Institute for Health and Clinical Excellence. Chronic Obstructive Pulmonary Disease (Update). Clinical guideline 101. 2010.

2. Wilkinson T, Donaldson GC, Hurst JR, et al. Early therapy improves outcomes of exacerbations of chronic obstructive pulmonary disease. Am J Respir Crit Care Med 2004:169:1298-303.

\section{P262 ORAMORPH FOR BREATHLESSNESS: IN PURSUIT OF GUIDELINES AND PATIENT INFORMATION FOR USE IN COPD}

doi:10.1136/thoraxjnl-2011-201054c.262

A Williamson, L Restrick, C Potter, S Purcell, S Roberts, B Coleman, M Stern. Whittington Health, London, UK

Introduction Breathlessness is the most common and frightening symptom in Chronic Obstructive Pulmonary Disease (COPD). Short-acting morphine (Oramorph) has traditionally been used to treat breathlessness in palliative care. Although used in COPD
(Simon et al, 2010), there is no consensus/guidelines for prescribing and patients stigmatise morphine, associating it with dying or addiction. In this study, we assessed current prescribing practice, patient use and safety of Oramorph, to inform local prescribing guidelines and patient information.

Method Case notes of patients who were prescribed Oramorph for breathlessness while having multidisciplinary COPD care between 2004 and 2011 were reviewed. The following were documented: patient demographics, disease severity $\left(\mathrm{FEV}_{1}, \mathrm{MRC}\right.$ dyspnoea score, nebulisers, long term oxygen therapy (LTOT), domiciliary NonInvasive Ventilation (NIV), social/healthcare support and palliative care referrals; Oramorph starting dosage, dosage range, increase in dosage, patient choice to continue, duration of and use of morphine sulphate slow release tablet (MST).

Results 28 COPD patients prescribed Oramorph for breathlessness were identified $(14 \mathrm{M})$, median (range) age $70(52-83)$ years $\mathrm{FEV}_{1}$ (mean \pm SD) $0.58 \pm 0.22$, MRC dyspnoea score 4.6 \pm 0.49 . 19/28 (68\%) were on LTOT, $28 / 28(100 \%)$ on nebulisers, $5 / 28$ (17\%) on domiciliary NIV, two current smokers, 10/28 (36\%) lived alone, 27/28 (96\%) had professional healthcare domiciliary visits, $8 / 28$ (29\%) had palliative care input. Starting, incremental and current dosing of Oramorph are shown in the Abstract P262 table 1.25/28 (89\%) patients chose to stay on Oramorph once started. Median (range) duration on Oramorph was 8 months ( 45 days -7.5 years). MSTwas added for breathlessness in three patients. $13 / 28(46 \%)$ patients died; all were MRC 5 and starting Oramorph was not felt to be a contributing factor by the clinical team. Time to death after starting Oramorph was median (range) 7 months (68 days-2.6 years). Oramorph prescribing in COPD increased year-on-year (one patient in 2004 to 12 in 2010).

Conclusion Oramorph prescribed by a respiratory team for breathlessness is safe in this group of patients. This study indicates that its effect is sustained despite low dosages with little requirement for incremental dosing over time. Guidelines for prescribing and patient information will be critical to ensure that patients are not denied this useful treatment of breathlessness.

\section{Abstract P262 Table 1}

\begin{tabular}{lll}
\hline Oramorph & Median dose $\mathbf{~ m g}$ & Range dose $\mathbf{~ m g}$ \\
\hline Starting dose $(\mathrm{n}=28)$ & $2.5 \mathrm{mg} \mathrm{bd}$ & $1.25 \mathrm{mg} \mathrm{bd}-5 \mathrm{mg}$ qds \\
Increase $(\mathrm{n}=12)$ & $2.5 \mathrm{mg} \mathrm{bd}$ & $2.5 \mathrm{mg} \mathrm{bd}-10 \mathrm{mg}$ qds \\
Current dose & $2.5 \mathrm{mg} \mathrm{bd}-2.5 \mathrm{mg}$ qds & $1.25 \mathrm{mg} \mathrm{bd}-10 \mathrm{mg}$ qds \\
\hline
\end{tabular}

\section{P263 CANNABIS USE, RESPIRATORY SYMPTOMS AND LUNG FUNCTION, IN A NORTH EDINBURGH PRIMARY CARE POPULATION}

doi:10.1136/thoraxinl-2011-201054c.263

${ }^{1} \mathrm{P}$ T Reid, ${ }^{2} \mathrm{~J}$ McKenzie, ${ }^{1} \mathrm{~L}$ Copeland, ${ }^{3} \mathrm{R}$ Elton, ${ }^{4} \mathrm{~J}$ Macleod, ${ }^{2} \mathrm{~J} \mathrm{R}$ Robertson. ${ }^{1}$ Western General Hospital, Edinburgh, UK; ${ }^{2}$ Muirhouse Medical Group, Edinburgh, UK; ${ }^{3}$ Department of General Practice, Edinburgh, UK; ${ }^{4}$ Department of Social Medicine, Bristol, UK

Background We are conducting a cross-sectional study of cannabis and tobacco smokers in a primary care population and reporting respiratory symptoms and lung function in two groups: Group $1=$ persons who smoke tobacco cigarettes (branded cigarettes $+/-$ "roll-your-own"); Group 2=persons who smoke cannabis +/tobacco cigarettes.

Methods Information on tobacco and cannabis smoking is obtained from the Avon Longitudinal Study of Parents and Children. Cumulative smoking is quantified by use of tobacco pack-years (py) and joint years (jy). Additional tobacco use in cannabis smokers is recorded. Other instruments used include the NHANES III and MRC breathlessness questionnaires, measurement of ventilatory capacity (Vitalograph $\alpha$ ) and the Scottish Indices of Multiple Deprivation 